\title{
Developing Human Capital Capabilities of Top Management Team for CoPS Innovation*
}

\author{
Yuhui GE, Weizhong YANG
}

School of Management, Shanghai University for Science and Technology, Shanghai, China.

Email: okyang95@gmail.com

Received May $11^{\text {th }}$, 2009; revised June 20 $0^{\text {th }}$ 2009; accepted July 26 $6^{\text {th }}, 2009$.

\begin{abstract}
Top management team (TMT) play key roles in many industries and firms. Human resources is continuously developed and considered to be a competitive advantage. Traditional research on TMT has, however, paid scant attention to the human capital capabilities of TMT needed for firms. Furthermore, traditional work on TMT of firms pays limited attention to its specific traits in complex products and systems (CoPS) innovation. In the present paper, we explore the development of human capabilities of TMT observed in CoPS innovation firms. We developed a model for analysis the human capital capabilities of TMT for CoPS Innovation, and suggested that a dynamic interplay between the development of human capital capabilities of TMT and the changing CoPS innovation environment, and human capital capabilities of TMT for CoPS innovation could be developed through team learning. And we formulated an empirical research framework for the analysis of factors affecting the human capital capabilities of TMT for CoPS innovation. Four key factors were identified and extracted by using factor analysis, and these resulting factors were related to the performance of CoPS innovation by using a multiple regression analysis method. The proposed framework identified four blocks of human capital capabilities of TMT for CoPS innovation, namely technology innovation management, risk management, organization management and relationship network management. The paper argues that TMT for CoPS innovation firms are only able to effectively harness and develop their human capital capabilities by team learning and integrating these four building blocks within the team.
\end{abstract}

Keywords: top management team, human capital capabilities, complex systems and products, learning, innovation performance, factor analysis, regression analysis

\section{Introduction}

Complex systems and products (CoPS) are a high-cost and high-tech subset of capital goods; they are produced on a project basis, often in multi-firm alliances, as one-offs or small bathes for large business, institutional and government customers. Examples include aircraft, telecommunication systems, flight simulators, high speed trains, air traffic control systems [1]. More and more emphases have been given on the performance of CoPS innovation, the ultimate goal of CoPS innovation is not just technical success, but also economic success. CoPS innovation requires a large amount of resources, while the human capital which is considered to be more important with respect to physical capital investment [2]. People's intelligence and ingenuity play a vital role in the process of CoPS innovation, and directly affect the

*This research is funded by Humanities \& Social Sciences Research Project, Ministry of Education (No. 06JA630042), and Shanghai Key Disciplines (Phase 3) (No.S30504). outcomes of CoPS innovation. Encouraging the CEO and senior executives to work as a team has been suggested as a way of enhancing strategic leadership effectiveness in complex organizations. Top management team (TMT) has been put forward as an element ideally suited for managing increasing complexity, fast changing markets, cross-functional business expertise, customer focused innovation and market, and technological uncertainty [3].

Chester Barnard's (1938) classic book The Functions of the Executive, scholars have attempted to explain how top management affects organizational outcomes. Cyertand March (1963) introduced the "dominant coalition" concept and Child (1972) advanced the notion of "strategic choice" to explain how top management influenced firm survival [4,5]. In contrast, scholars, such as Aldrich (1979), and Astley and Vande Ven (1983), have argued that business environments are too complex for manag- 
ers to mattering a significant way. In response to this debate, and spawned by Hambrick and Mason's (1984) "upper echelon theory", a long line of research ensued linking top management team composition, measured by demographic age, tenure, and education with organizational outcomes [6], strategy, strategic change and performance $[7,8,9]$. The contention of much of this composition research was that top management's experiences and values affects organizational outcomes through strategic decision- making. During the 90s, and drawing from team process research, scholars began to examine attributes of top management process, such as how the team gets along or the formality of its operation. For example, Smith et al. (1994) found a positive relationship between top management social integration and performance and O’Reilly, Snyder, and Boothe (1993) reported a negative connection between top management cooperation with the extent of strategic change [10,11]. Like the composition research, the process work contended that the manner by which top management interacted and communicated would influence organizational outcomes through strategic decision-making. More recent contributions also have demonstrated that both top management composition and process are related to organizational outcomes such as innovation and profitability. Moreover, there is evidence that demography and process are interrelated, such that the composition of the team affects the process of interaction [12]. The work of foregoing scholars enriches theory on TMT. Scholars have made big progress in TMT research.

Nonetheless, there are some limitations of the abovementioned research. First of all, the relationship between external influences (e.g. scientific, technological, market, economic factors, other staff, rules and regulations) and the internal capabilities of TMT has not addressed the issue of top management team by the contingency theory perspective on organizational development and its environment. The top management team characteristics, team dynamics are very different in the CoPS innovation, and their impacts on performance of CoPS innovation are also different. Secondly, these TMT researches have excessively focused on how TMT demographic characteristics or individual personalities, cognitive preference effect performance, while neglecting the hidden insights of these digital characteristics. TMT are able to explore, experiment, innovate and make decision in the supply of CoPS by building human capital capabilities necessary to supply CoPS. In the TMT literature a few recent studies have focused on human capital capabilities (HCC) of TMT affecting outcomes, especially in the production of CoPS. Ge Y. H. (2007) first advanced the TMT research methodology based on human capital, and establishe model describing the relationship between the factors of TMT's human capital value and the enterprise performance [13]. However, in its initial stage, systematic research on human capital capabilities of TMT for CoPS innovation is still in exploration phase.

\section{Building Human Capital Capabilities of TMT for CoPS Innovation: A Framework of Normative Analysis}

\subsection{Interaction Model of Human Capital Capabilities of TMT for CoPS Innovation}

TMT human capital is scarce in the state of the market, and its capabilities are indispensable in the management of CoPS production and can been seen as a variable factor of production function. In the face of uncertain conditions, they are critical to the ability of the firm to allocate, integrate and coordinate all kinds of resources. The effectiveness of human capital capabilities of TMT or TMT effectiveness is related to changes in the external environment and assumptions about this relationship have influenced the progress of unstructured tasks.

As Figure 1 shows, the interaction model system is composed of CoPS innovation activities (including marketing, R\& activities and production), TMT, other staff, and market, organizational and technical environment. The elements of the model are interactive and influencing each other, and together promoting and realizing the CoPS innovation. the crux of the model is TMT, for its abilities are essential for the CoPS innovation, while the periphery are CoPS innovation activities other staff, and market, organizational and technical environment, which constitute the TMT environment.

We argue that the achievement of CoPS innovation is, to a large extent, attributed to the TMT, and human capital capabilities of TMT are critical for CoPS innovation. A conservative, not innovative TMT are hard to claim the credit in CoPS innovation. The main functions of TMT in CoPS innovation are as follows:

- $\quad$ Participating effectively in the selection and bid of CoPS innovation projects.

- $\quad$ Supporting the R\&D activities.

- Purchasing resources inside and outside the firm, and managing and reallocating resources through the CoPS innovation project life cycle using milestones and deadlines.

- Working in a dynamic environment, coping with risk avoidance and control, handling unexpected 


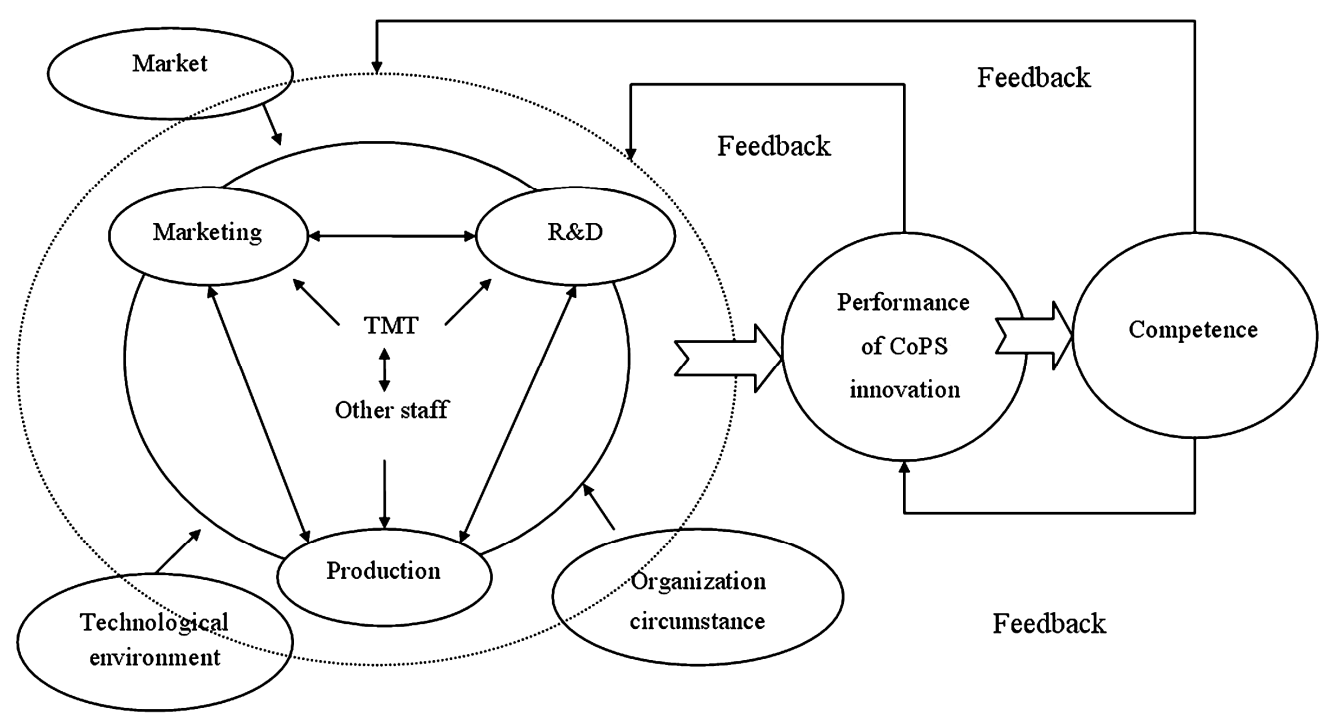

Figure 1. Interaction model of human capital capabilities of TMT for CoPS innovation

incidents, and managing conflicts [14].

- Using a number of tools, techniques and concepts - e.g. concurrent engineering, milestone scheduling and PERT_Program Evaluation and Review Technique [15].

- Instructing and selecting suitable staff for various CoPS innovation activities, and formatting incentive and restrictive mechanism.

- $\quad$ TMT social integration network are general positively associated with innovation activities. Managing social integration network is of great importance for CoPS.

TMT are responsible for the completion of CoPS innovation within costs, on schedule and to specified standards. The effectiveness of TMT lies in its human capital capabilities. If the human capital capabilities are not concordant with the CoPS innovation, and then the performance of CoPS innovation will be undesirable.

In the other way, in response to increasing complexity in production, communication and technology, and achieving high level of CoPS innovation performance, which is feedback to CoPS innovation activities and TMT, developing human capital capabilities is the only way out. The relationship between external influences and the internal characteristics of TMT can been specifically addressed by the contingency theory perspective on human capital capabilities development. To remain effectively related to rapidly changing environments, firms are periodically faced with the challenge of re-deploying their existing resources and changing their internal processes and capabilities.

\subsection{Developing Human Capital Capabilities of TMT for CoPS Innovation through Learning}

Lessons learned from the CoPS innovation project and recommendations for improvements can be transferred to TMT. Figure 1 shows a dynamic interplay between the TMT human capital capabilities and the changing external conditions, recognizing that synergetic development and learning are the main way to improve the performance of CoPS innovation. Learning are seen as important in improving organizational performance in relation to developing capabilities in continuous improvement in manufacturing [16]; by Bartezzaghi et al. (1997) and Caffyn (1997) with respect to improving the new product development process [17]; and by Coombs and Hull (1997) in relation to the mechanisms through which knowledge affects possibilities for innovation [18].

CoPS innovation performance and changes in the environment necessitate systematic changes in the entire organization - a change in one part of the organization requires complimentary changes in other parts. Providers of CoPS from project to project have to think and act differently -they need to enter into new relationships with their customers, to take on different risks and implement new means of assuring quality [19]. These require that the firms and TMT enhance their existing capabilities to include the ability to R\&D, marketing, manufacturing and production, risk management, and relationship network management. In addition they need to develop business consulting capabilities- to understand a customer's business and to offer advice and solutions that dress the customer's specific business needs; and financing capabilities - to provide the customer with help in purchasing new systems and in managing their installed base of assets. 


\section{Building Human Capital Capabilities of TMT for CoPS Innovation: A Framework of an Empirical Study}

This section builds upon scholars' insights and above analysis in seeking through an empirical study of 133 respondents to explore the factors affecting human capital capabilities of TMT within firms producing CoPS by factor analysis and regression analysis.

\subsection{Research Framework}

A thorough literature review and Nominal Group Technique (NGT) were used to identify factors of project competence in CoPS as recognized by research and practitioners in this field. Then a questionnaire was developed to identify and rank their associated measured variables. Using factor analysis, the most important variables affecting human capital capabilities of TMT for CoPS innovation were identified and extracted to new key factors, and the multiple regression method was applied on the new key factors to define the contribution of these factors to the performance of CoPS innovation.

Factor Analysis is a technique for finding a small number of underlying dimensions from among a large number of variables. This technique was used in this study to explore the possible underlying factor structure of 16 sets of measured variables. By performing factor analysis, the underlying factor is identified, and data reduction is achieved. The factor analysis model is given by:

$$
Y=X \alpha+E
$$

where, $Y$ is a matrix of measured variables; $X$ is a matrix of common factors; $\alpha$ is a matrix of weights (factor loadings); and $E$ is a matrix of unique factors, error variation.

After obtaining the $X$, we related these resulting factors to the performance of CoPS innovation by using multiple regression analysis. Using standardized variables in multiple regression analysis, the estimating equation is:

$$
Z_{j}=\sum \beta_{i} X_{i}+F
$$

where, $X_{i}$ is the matrix of common factors reproduced from measured variables; $Z_{j}$ is one of dimensions that predicting the performance of CoPS innovation; $\beta_{i}$ is a matrix of coefficients; and $F$ is a matrix of error variation.

\subsection{Questionnaire Design and Sampling}

In this empirical research, we generate 5 sets of factors, and 16 measured variables. Combining the results of the literature review with the results of our survey, the overall factors affecting human capital capabilities of TMT for CoPS innovation were identified. 3 dimensions mediating variables and 6 measured variables were generated to measure the performance of CoPS innovation.

A questionnaire survey was then developed and used as a research tool to asses and rank these variables. The rating scale was a one-to-ten Likert scale, ranging from extremely confident (10 points) to not confident at all (1point), was used to measure subjects' confidence in their judgment. 42 firms that producing CoPS participated in responding to the questionnaire. About 265 questionnaires were sent out along with a letter. This letter detailed the purpose of this study, and encouraged the TMT members to participate without disclosing personal information. The number of returned questionnaires was 165 , but after a procedure of pre-filtering, only 133 were usable.

\subsection{Primary Data Analysis}

The data meet Kaiser-Meyer-Olkin's sample adequacy criteria (0.851, minimum acceptable level 0.60 ), as well as those for Bartlett's test of sphericity

$$
\left(\chi^{2}=727.01, P<0.0001\right)
$$

for the appropriateness of using factorial models. Internal consistency of measures must be verified, as shown in Table 1, these estimates of cronbach's alpha coefficients and full scale range from 0.53 to 0.86 , which are approaching the threshold of 0.60 suggested by Jöreskog and Sörbom and thus acceptable. Internal consistency is implied [20].

The mean, standard deviation and corrected item-total correlation of the 16 measures for 133 respondents are presented in Table 1 . The item-total correlation shows acceptable coefficients for all variables $(P<0.05$ and higher), ranging from 0.04 to 0.63 . The following measures, resource allocation (Measure 7) and leadership (Measure 9), yield the highest correlation coefficient. Human resources management (Item11), communication and coordination (Measure 10), and resource allocation (Measure 7) are the major agreements of respondents (ranging from 5.02 to 5.28). R\&D management is comparatively the least measured variable, nevertheless they are significantly correlated $(P<0.05)$ with the underlying construct. Therefore, this indicates their relative specificity for human capital capabilities construct.

\subsection{Factor Analysis}

There are generally two steps in factor analysis: namely, the extraction of factors and the rotation of the factors. The 16 measures were assumed to be independent variables. 
Table 1. Frequency and internal consistency of factors s of HCC and performance of CoPS innovation

\begin{tabular}{|c|c|c|c|c|}
\hline Constructs (factors) & Measured variables & $\begin{array}{l}\text { Cronbach's } \\
\text { alpha }\end{array}$ & $\begin{array}{l}\text { Frequency } \\
(\text { mean } \pm S D)\end{array}$ & $\begin{array}{l}\text { Corrected } \\
\text { item-total correla- } \\
\text { tion }\end{array}$ \\
\hline \multirow{3}{*}{$\begin{array}{l}\text { Technology innovation } \\
\text { management (TIM) }\end{array}$} & 1. R\&D management & \multirow{3}{*}{0.53} & $5.45 \pm 1.89$ & 0.07 \\
\hline & 2. Technology management & & $6.12 \pm 1.63$ & 0.50 \\
\hline & 3. Commercial innovation & & $6.43 \pm 1.65$ & 0.55 \\
\hline \multirow{3}{*}{ Risk management (RM) } & 4. Risk avoidance and control & \multirow{3}{*}{0.63} & $7.41 \pm 1.32$ & 0.45 \\
\hline & 5. Unexpected incidents handling & & $7.32 \pm 1.37$ & 0.41 \\
\hline & 6. Conflicts management & & $7.32 \pm 1.37$ & 0.18 \\
\hline \multirow{5}{*}{$\begin{array}{l}\text { Organization manage- } \\
\text { ment (OM) }\end{array}$} & 7. Resource allocation & \multirow{5}{*}{0.86} & $7.44 \pm 1.31$ & 0.65 \\
\hline & 8. Team work & & $7.17 \pm 1.66$ & 0.52 \\
\hline & 9. Leadership & & $7.30 \pm 1.78$ & 0.70 \\
\hline & 10. Communication and coordination & & $7.69 \pm 1.39$ & 0.58 \\
\hline & 11. Human resources management & & $7.61 \pm 1.28$ & 0.55 \\
\hline \multirow{2}{*}{ Operational process (OP) } & 12. Planning & \multirow{5}{*}{0.62} & $7.17 \pm 1.61$ & 0.59 \\
\hline & 13. Execution & & $6.45 \pm 1.60$ & 0.58 \\
\hline \multirow{3}{*}{$\begin{array}{l}\text { Relationship network } \\
\text { management (RNM) }\end{array}$} & 14. Business relationship network & & $6.50 \pm 1.69$ & 0.58 \\
\hline & 15. Internal social integration & & $7.09 \pm 1.37$ & 0.46 \\
\hline & 16. Government relationship network & & $6.49 \pm 1.49$ & 0.04 \\
\hline \multirow{2}{*}{ R\&D performance (RDP) } & 1. Patents increasing & \multirow{2}{*}{0.73} & $6.67 \pm 1.45$ & 0.58 \\
\hline & 2. Increasing new products & & $6.63 \pm 1.59$ & 0.58 \\
\hline $\begin{array}{l}\text { Production } \\
\text { \& manufacturing per- } \\
\text { formance (PMP) }\end{array}$ & 1. Improving cost efficiency & & $6.88 \pm 1.32$ & \\
\hline \multirow{3}{*}{$\begin{array}{l}\text { Business performance } \\
\text { (BP) }\end{array}$} & 1. Increasing growth rate & \multirow{3}{*}{0.83} & $6.88 \pm 1.66$ & 0.68 \\
\hline & 2. Increasing market share & & $7.05 \pm 1.57$ & 0.65 \\
\hline & 3. Improving overall profitability & & $7.05 \pm 1.60$ & 0.72 \\
\hline
\end{tabular}

Table 2. Rotated component matrix after varimax rotation from PAC of factors of HCC of TMT for CoPS innovat

\begin{tabular}{|c|c|c|c|c|c|}
\hline Variables & $\begin{array}{c}\text { Factor } 1 \\
\text { Technology } \\
\text { innovation } \\
\text { management }\end{array}$ & $\begin{array}{c}\text { Factor } 2 \\
\text { Risk man- } \\
\text { agement }\end{array}$ & $\begin{array}{c}\text { Factor } 3 \\
\text { Organization } \\
\text { management }\end{array}$ & $\begin{array}{c}\text { Factor } \mathbf{4} \\
\text { Relationship } \\
\text { network man- } \\
\text { agement }\end{array}$ & $h^{2}$ \\
\hline 1. R\&D management & 0.66 & & & & 0.54 \\
\hline 2. Technology management & 0.71 & & & & 0.66 \\
\hline 3. Commercial innovation & 0.71 & & & & 0.71 \\
\hline 4. Risk avoidance and control & & 0.68 & & & 0.54 \\
\hline 5. Unexpected incidents handling & & 0.70 & & & 0.58 \\
\hline 6. Conflicts management & & 0.79 & & & 0.63 \\
\hline 7. Resource allocation & & & 0.76 & & 0.62 \\
\hline 8. Team work & & & 0.75 & & 0.57 \\
\hline 9. Leadership & & & 0.65 & & 0.62 \\
\hline 10. Communication and coordination & & & 0.76 & & 0.60 \\
\hline 11. Human resources management & & & 0.55 & & 0.45 \\
\hline 12. Planning & & & 0.74 & & 0.60 \\
\hline 13. Execution & & & 0.70 & & 0.55 \\
\hline 14. Business relationship network & & & & 0.69 & 0.70 \\
\hline 15. Internal social integration & & & & 0.62 & 0.57 \\
\hline 16. Government relationship network & & & & 0.82 & 0.71 \\
\hline Eigen value & 4.33 & 2.00 & 1.68 & 1.63 & 8.64 \\
\hline$\%$ of variance explained & $27.08 \%$ & $12.51 \%$ & $10.47 \%$ & $10.17 \%$ & $61.23 \%$ \\
\hline$h^{2}=$ final communality estimates & & & & & \\
\hline
\end{tabular}


Principal component analysis (PCA) was used to explore the factor structure of factors of human capital capabilities of TMT for CoPS innovation.

Table 2 shows that $61.23 \%$ of the total variance is attributed to the first 4 factors, where these factors have an eigen value greater than 1.00 . The remaining factors account together for $38.77 \%$ of the variance. The scree plot also verifies the above findings. Thus 4 factors should be considered adequate to represent the data. Once a set of common factors have been identified, there remains the question of how the individual variables relate to those common factors. A varimax rotation method was used in this study to explore the relationship. The factor rotation results indicate the new factors and their variables related to each factor. It also shows the strength of correlation between the new factors and their variables. Inspection of communality estimates $\left(h^{2}\right)$ reveals a very high value $(>0.50)$ for all variables [21]

As a result, the factor analysis technique reduced the 16 variables to 4 new factors. These new factors can be renamed as shown in Table 2, measured variables 12 and 13 of operation process construct and variables of organizational management construct can be integrated as one factor, named organizational management.

\subsection{Regression Analysis}

We turned to a regression analysis, which would allow us to test empirically which factors of human capital capabilities of TMT for CoPS innovation are closely correlated with the performance of CoPS innovation, which are not.

The performance of CoPS innovation was assessed judgmentally by mediating variables R\&D Performance, production \& manufacturing performance, and business performance. Each mediating variables are predicted by several manifest variables. Figure 2 shows the conceptual model that describing the interrelationship between two sets of constructs-the human capital capabilities of TMT and the CoPS innovation performance. The first set is comprised of technology innovation management (TIM), risk management (RM), organization management (OM), operational process (OP), and relationship network management (RNM) deemed to conducive to higher level of performance of CoPS innovation, whereas the second sets of constructs represent R\&D performance (RDP), Production \& manufacturing performance (PMP), and Business performance (BP) of human capital capabilities of TMT.

The 4 new factors of human capital capabilities of TMT were unitized as independent variables to determine usefulness for predicting changes in the independ- ent variables, R\&D performance, production \& manufacturing performance and business performance. Table 3 summarizes the results obtained in the regression analysis with the SPSS 15.0 for windows software. Based on the aforementioned regression analysis, the following reduced model [Equations (1) and (2)] was postulated as a prediction tool.

$\mathrm{R} \& \mathrm{D}$ performance $=-2.84+0.50 * \mathrm{~F} 1$ (Technology innovation management) $+0.21 * \mathrm{~F} 2$ (Risk management) $+0.19 *$ F3 (Organization management) + 0.13*F4 (Relationship network management).

Production \& manufacturing performance $=-2.96+$ $0.31 * \mathrm{~F} 1$ (Technology innovation management) + $0.09 * \mathrm{~F} 2$ (Risk management) $+0.34 * \mathrm{~F} 3$ (Organization management) $+0.25^{*} \mathrm{~F} 4$ (Relationship network management).

Business performance $=-2.62+0.26 * \mathrm{~F} 1$ (Technology innovation management) $+0.18 * \mathrm{~F} 2$ (Risk management) $+0.20 * \mathrm{~F} 3$ (Organization management) $+0.18 * \mathrm{~F} 4$ (Relationship network management).

Significant standardized regression coefficients confirmed the positive relationship between factors of human capital capabilities of TMT and performance of CoPS innovation.

The explanatory power of the model was also shown in Table 3. The values of $R^{2}(0.35,0.28$, and 0.17$)$ are sufficient to represent the most important factors affecting performance of CoPS innovation.

\subsection{Developing Blocks of Human Capital Capabilities of TMT for CoPS Innovation}

Given the results from factor analysis, regression analysis, the proposed model identified 4 building blocks of human capital capabilities of TMT for CoPS innovation, namely technology innovation management, risk management, organization management and relationship network management. These building blocks are highly related to performance of CoPS innovation, and they are strongly correlated with each other.

However, the relationship between the building blocks should be pointed out. For instance, we acknowledge the relationship between organization management capabilities and risk management capabilities, but also that existing logics of organization management capabilities has effects on the risk management capabilities. Similar relationships are found between other human capital capabilities.

We argue that the TMT who are in charge of CoPS innovation must produce a dynamic fit between the building blocks of human capital capabilities. Furthermore, 
Human capital capabilities of TMT

Performance of CoPS innovation

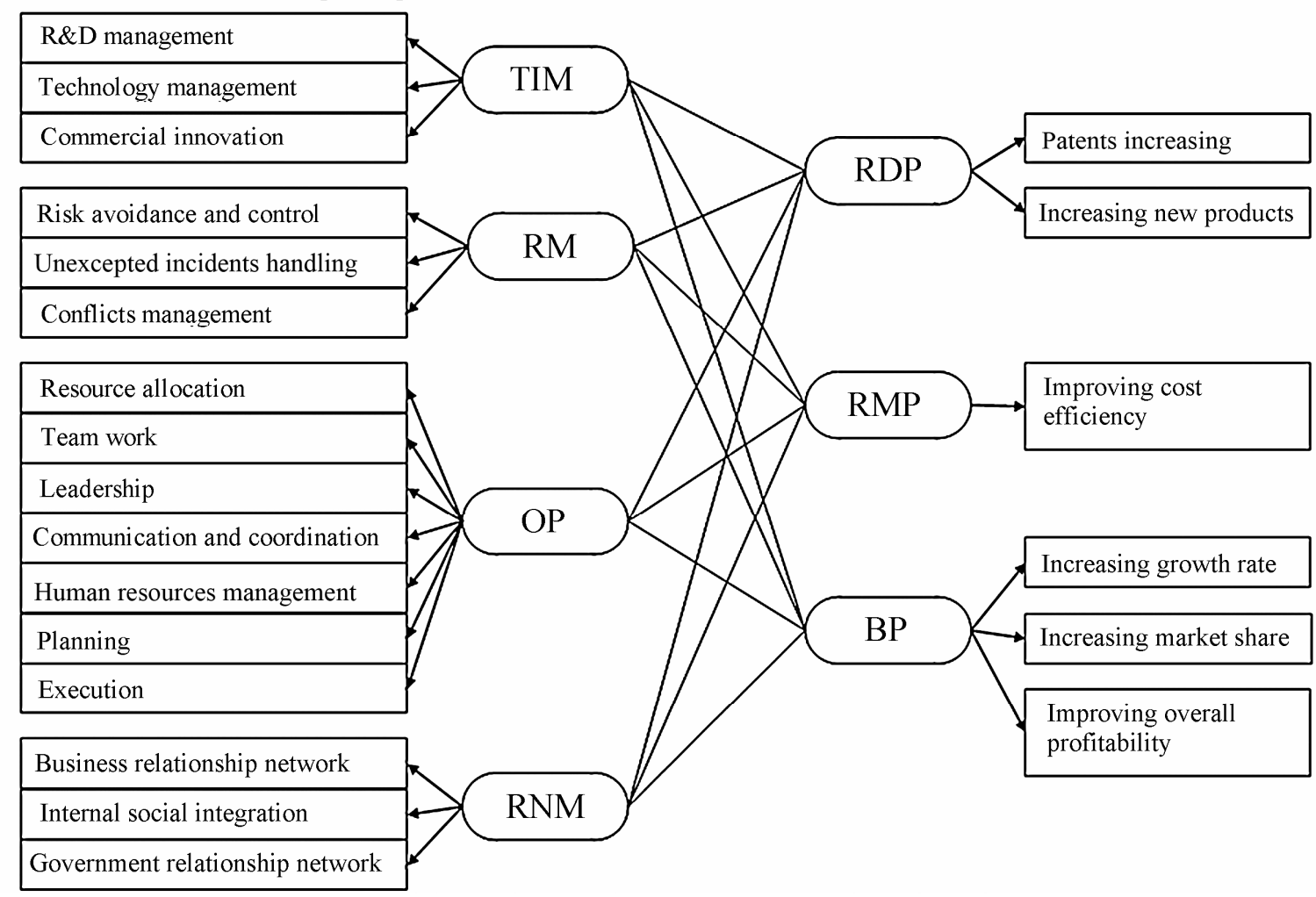

Figure 2. Interrelationship between human capital capabilities of TMT and CoPS innovation performance

Table 3. Regression coefficients $(\mathrm{N}=133) \mathrm{T}$

\begin{tabular}{lccc}
\hline Variables & R\&D performance & $\begin{array}{c}\text { Production \& manufacturing per- } \\
\text { formance }\end{array}$ & Business performance \\
\hline Technology innovation man- & $\begin{array}{c}\text { Standardized } \\
\text { coefficients (Beta) }\end{array}$ & $\begin{array}{c}\text { Standardized } \\
\text { coefficients (Beta) }\end{array}$ & $\begin{array}{c}\text { Standardized } \\
\text { coefficients (Beta) }\end{array}$ \\
agement & 0.50 & 0.31 & 0.26 \\
Risk management & 0.21 & 0.09 & 0.18 \\
Organization management & 0.19 & 0.34 & 0.20 \\
Relationship network manage- & 0.13 & 0.25 & 0.18 \\
ment & 0.35 & 0.28 & 0.17 \\
$R^{2}$ & $>1.84$ & $>1.19$ & $>2.19$ \\
t-value & $>0.00$ & $>0.00$ & $>0.02$ \\
Sig. & & & \\
\hline
\end{tabular}

a change in one building block capabilities might have severe consequence on one or more of the other building blocks. For instance, the risk avoidance and control capabilities would have effect on the efficiency of R\&D management. Moreover, some CoPS innovation projects generated might lack necessary leadership capacity because of the complexity and uncertainty of them.

In the business CoPS innovation projects we can find some clear examples of this, for instance, key project leaders lack the necessary knowledge about a certain category of client. In other cases, leaders lack the necessary skills for dealing with a new (and more uncertain) technology. Additionally, we can observe that an increase in project leadership capacity also had some obvious effects on a series of capabilities, ranging from human resource management to unexpected incidents handling.

\section{Conclusions}

TMT in CoPS innovation, featuring as working in high 
degree of complexity and uncertainty and adapting in the changing environment, is open system. Its work environment plays a role in the formation and application of human capital capabilities of TMT, in turn; human capital capabilities of TMT for CoPS innovation have a positive influence on its working environment and the performance of CoPS innovation. Different types of human capital capabilities of TMT are corresponding to diverse environmental characteristics. Several implications are drawn from this study.

- Human capital capabilities of TMT is an indispensable elements for CoPS innovation;

- The development of human capital capabilities of TMT is confined to CoPS innovation environment;

- Human capital capabilities of TMT for CoPS Innovation would be developed through learning;

- Human capital capabilities of TMT for CoPS innovation consists of four building blocks: technology innovation management, risk management, organization management, and relationship network management;

- These building blocks are highly related to performance of CoPS innovation, and they are strongly correlated with each other, changes in one building block of human capital capabilities of TMT might have severe consequence on the other building blocks.

- Human capital capabilities of TMT is constituted in the fit and dynamics between the identified building blocks; and

TMT for CoPS innovation firms are only able to effectively harness and develop their human capital capabilities by team learning and integrating these four building blocks within the team.

The development of human capital capabilities of TMT for CoPS innovation elaborated upon in this paper thus rests upon these elements. We are, no doubt, aware of the problems in drawing such a result. The propositions given in this paper should be tested and compared between firms and industries in order to further our understanding of human capital capabilities of TMT for CoPS innovation and its development.

\section{Acknowledgements}

The authors are also grateful to anonymous referees for their helpful comments and insights. This research is funded by Humanities \& Social Sciences Research Project, Ministry of Education (No. 06JA630042), and Shanghai Key Disciplines (Phase 3) (No. S30504).

\section{REFERENCES}

[1] R. Miller, M. Hobday, T. Leroux_Demers, and X. Olleros, "Innovation in complex system industries: The case of flight simulators," Industrial and Corporate Change, No. 2, pp. 63-400, 1995.

[2] F. H. Xie, X. G. Yao, and J. J. Gu, “An empirical study on relation between enterprise top management team's heterogeneity and enterprise technological innovation performance,” Science Research Management, No. 29, pp. 65-73, 2008.

[3] C. F. Chang, "The impacts of top management team characteristics and entrepreneurial orientation on management competence and performance,” National Chen Kung University, Institute of Business Administration Master's Thesis, 2005.

[4] R. M. Cyert and J. G. March, “A behavioral theory of the firm,” Englewood Cliffs, Prentice-Hall, NJ, 1963.

[5] J. Child, "Managerial and organizational factors associated with company performance,” Journal of Mangement Studies, No. 11, pp. 13-27, 1974.

[6] D. C. Hambrick and P. A. Mason, "Upper echelons: The organization as a reflection of its top managers," Academy of Management Review, No. 9, pp. 193-206, 1984.

[7] J. G. Michel and D. C. Hambrick, "Diversification posture and the characteristics of the top management team," Academy of Management Journal, No. 35, pp. 9-37, 1992.

[8] M. F. Wiersema and K. A. Bantel, “Top management team demography and corporate change,” Academy of Management Journal, No. 35, pp. 91-121, 1992.

[9] D. C. Hambrick and R. D’Aveni, “Top management team deterioration as part of the downward spiral of large corporate bankruptcies," Management Science, No. 38, pp. 1445-1466, 1992.

[10] K. G. Smith, et al., “Top management team demography and process: The role of social integration and communication,” Administrative Science Quarterly, No. 39, pp. 412-438, 1994.

[11] C. A. O’Reilly and J. N. Boothe, "Executive team demography and organizational change,” In G. P. Huber and W. H. Glick (eds.), Organizational Change and Redesign: Ideas and Insights for Improving Performance, Oxford University Press, New York, 1993.

[12] D. C. Knight, et al., "Top management team diversity, team process, and strategic consensus," Strategic Management Journal, No. 20, pp. 445-465, 1999.

[13] Y. H. Ge, "Research of the relationship model between top management team and enterprise performance based 
on huaman capital value factors," Science of Science and Management, No. 8, pp. 160-165, 2008.

[14] A. Davies and T. Brandy, "Organisational capabilities and learning in complex product systems: Towards repeatable solutions,” Research Policy, No. 29, pp. 931955, 2000.

[15] D. M. Gann and A. Salter, "Innovation in project-based, service-enhanced firms: The construction of complex products and systems," Research Policy, No. 29, pp. 955-972, 2000.

[16] S. Caffyn, "Extending continuous improvement to the new product development process," R\&D Management, No. 27, pp. 3, 1997.

[17] E. Bartezzaghi, M. Corso, et al., "Continuous improvement and inter-project learning in new product development,” International Journal of Technology Management, No. 14, pp. 1, 1997.
[18] R. Coombs and R. Hull, "Knowledge management practices and path-dependency in innovation,” CRIC Discussion Paper, Manchester, No. 2, 1997.

[19] A. Davies, T. Brady, D. Gann, et al., "Integrated solutions: The new economy between manufacturing and services,” Report, 2001.

[20] L. Raymond and J. St-Pierre, “Antecedents and performance outcomes of advanced manufacturing systems sophistication in SMEs,” Journal of Operations \& Production Management, No. 25, pp. 511-533, 2005.

[21] Y. P. Wang, C. T. Teng, A. H. G. Vieira Filho, C. Gorenstein, and L. H. Andrade, "Dimensionality of the premenstrual syndrome: Confirmatory factor analysis of premenstrual dysphonic symptoms among college students,” Brazilian Journal of Medical and Biological Research, No. 40, pp. 639-647, 2007. 